\title{
Harvesting IP-Based Value Potential: The Intellectual Property Scorecard As A Mechanism To Capitalize On Technological Innovation, Knowledge, And IP
}

\author{
IRFAAN KHOTA \\ Research Group for Engineering and Technology Management \\ Rizqapital Management, University of Johannesburg \\ Johannesburg, Gauteng Province, Republic of South Africa \\ irfaan.khota@gmail.com \\ LEON PRETORIUS \\ Department of Engineering and Technology Management \\ Graduate School of Technology Management \\ University of Pretoria, Pretoria, Gauteng Province, Republic of South Africa \\ leon.pretorius@up.ac.za
}

\begin{abstract}
There is a staggering decline in the capitalization of intellectual property (IP) and low levels of investment in $R \& D$, particularly with respect to emerging nations within the global IP environment, which limits accelerated industrial growth. In most emerging markets, this necessitates that management address multiple competencies better, that exploit organizational resources, knowledge, and management ability, to adapt faster than the competition. Our research offers a management model to address this management challenge strategically.

This research also indicates that IP as a value creation mechanism is currently not a top management priority although investors increasingly look toward good IP management as an indicator of future organizational growth. The research presents the IP Scorecard, a further inductive development of Kaplan and Norton's traditional Balanced Scorecard. The IP Scorecard is a strategic management tool that enables management to drive a robust industrial growth strategy that is explicitly positioned within the knowledge economy, identifying target areas for organizational development around knowledge and IP management, in order to achieve the competitive higher-ground, by strategically creating and capitalizing on value arising from innovation and R\&D activities.

The IP Scorecard sensitizes management on where and how to carve out competitive turf, particularly from a knowledge and IP value creation perspective, seeking ultimately to enhance corporate/shareholder and product-life-cycle value. The paper encompasses limited field research findings on key IP-related strategic management considerations that promote leadership in innovation and R\&D, across the product life cycle.
\end{abstract}

Keywords: Intellectual property; strategy; value-creation. 


\section{Introduction and Research Method}

\subsection{Research method}

The research presented in this paper extends on the findings presented at PICMET [Khota and Pretorius (2008b)]. The research encompasses inter alia (i) strategic considerations affecting producers and manufacturers; (ii) identification of incubators of competitive advantage within the knowledge economy; (iii) the IP Scorecard as a tool to optimize on IP-based value creating organizational activities; and (iv) limited field research.

The research focuses on the inductive development of Kaplan and Norton's Balanced Scorecard that identifies areas for development in knowledge management, and specifically the required strategic management stance demanded from product developers and innovators with respect to IP, to achieve the competitive highground. Inductive reasoning in research as used in this research is presented by Cooper and Schindler [2006] as an effective method especially in the early stages of research and for explorative research.

\subsection{Introduction: producers within the global competitive landscape}

The sources of economic growth now encompass both the traditional increases in the purchasing power of the population, as well as the explosion and application of new technologies that alter the business models and spending patterns of consumers [Garelli (2006)]. In a context where global economic growth is driven by the emergence of new markets, competitiveness depends on the management of multiple competencies in order to exploit resource and knowledge capital, together with the management ability to adapt better and faster than the competition to the dynamic and complex competitive landscape [Garelli (2006)].

The top rankings of Switzerland and the Nordic countries in global competitiveness show that a successful boost in competitiveness in an increasingly complex global economy is attainable through good institutions, competent macroeconomic management, world-class educational attainment, good healthcare, market efficiency, business sophistication, and a focus on technology, innovation, and investment in R\&D [WEFORUM (2007, 2006b)]. In emerging economies focused on industrial growth as a development strategy, $\mathrm{R} \& \mathrm{D}$ is a requirement for competitiveness [WEFORUM (2006b)], and the basis of competitive advantage and the new core business is the development and deployment of intangible assets (knowledge) [Teece (2001)].

Within the "IP" arena, Patents are accepted internationally as a reflection of a country's inventive and technological achievements and are used for monitoring and assessing national systems of innovation [Pouris (2005)].

\subsection{The challenge for innovators and product developers specifically}

Globalization, technological advances, changing customer needs, shorter product life cycles, and increased world competition drive new product introductions [Cooper (2001)], where a firm's competitiveness depends on its ability to connect 
and manage its numerous assets and promote participation in the global network of infrastructure [Garelli (2006)]. The management challenge for export growth is thus to expand manufacturing in the current comparative advantage sectors coupled with an expansion of service driven sectors (through investment in transport, technological and communications infrastructure) [Krakoff (2003); WEFORUM (2007)].

\section{Literature Review and Exploratory Research}

\subsection{The key strategic drivers to consider in targeting manufacturing and innovation growth}

Innovation has been defined as the embodiment, combination, or synthesis of knowledge in original relevant, valued new products, processes, or services [Luecke and Katz (2003)]. Competencies in developing innovation, together with efficiency, customer relations, distribution, and technology that aligns with the organization's overall strategy, create value [Ulrich and Smallwood (2003)]. The pace of change continues unfettered, and innovation is recognized as a key environmental and contextual change driver [Marton-Lefevre et al. (2003)] and a key source for sustainable solutions [UN (2008)].

Good innovation management is a key management lever to business growth and development challenges. Organizational conditions that promote innovation and knowledge-creation include access to capital, flat hierarchies, minimal bureaucracies, and the autonomy to try new things and possibly fail [Teece (2001); Von Krogh et al. (2000)]. From a technology and product development perspective, methodologies should generally adapt with context. Historically, increasing productivity has been driven by strategic management in (i) operational improvement in quality and reengineering; (ii) cost savings through outsourcing; and (iii) taking advantage of national comparative advantages through globalization.

Successful innovation and product development in the new context differ from historical methodologies. Off-shoring and outsourcing are now a key part of the globalization strategy of companies [Barloworld (2007); Welborn and Kasten (2005)], coupled with a major revolution underway where emerging economies are now competing not only with cheap manpower but also with cheap brainpower driven by the desire, attitude, and ambition to be competitive and thus create wealth [Garelli (2006); Teece (2001)].

Coming from a leadership paradigm that encourages experimentation in order to learn [Farber (2004)], product development within this context requires effective management strategies that overcome the "innovator's dilemma" by learning to do many things right [Anderson (2005); Christensen and Raynor (2003); Christensen (1997)]. The impact of the current context of rapid product development on management approach requires inter alia: smaller teams, product simplicity, attention to industrial design, flexible/cost-effective global manufacturing alliances (e.g., China), particular marketing prowess (including physical store, internet, licensing/ distributors etc.) and legal diligence [Baker (2008)]. As Baker [2008] indicates, 
management need to recognize two significant contextual product development requirements: (i) that each of the five phases of technology/product development (i.e., concept design, design development, detailed development, preproduction, and production) are now considered fundamental; and (ii) that product design, manufacturing, planning, and marketing development need to happen simultaneously rather than sequentially.

Stimulating innovation should be a key management focus area [Marton-Lefevre et al. (2003)], and achieving this requires a strategic management approach that is holistic, multidimensional, and targeted. In terms of value considerations that are multifacetted, management must: (i) strategize, measure, and manage both tangible and intangible value creation drivers [Ulrich and Smallwood (2003)]; (ii) create a positive corporate reputation that influences investor decisions and drives up sales [Hancock (2005); Jackson (2004)]; and (iii) adopt sustainable business strategies that necessarily address value creation from the perspective that it is sensitive to, maps and manages the evolving context, resources application, and opportunities facing the business environment [Khota and Pretorius (2008a); Khota et al. (2004)].

Given the enormous prevailing environmental and contextual challenges that require strategic robust innovation to solve them, design, development, deployment activities across the context, resources, and opportunity arenas must be sensitive to industrial (i.e., technical, market, and financial sensitivities) innovation from the perspective that management's focus must promote inter alia the responsible creation and utilization of new knowledge within the knowledge economy that is manifested responsibly into robust industrial innovations that address challenges from a holistic perspective (a "triple bottom line" management approach [Jackson (2004); Ulrich and Smallwood (2003)].

Our research suggests nine strategic focus areas spanning across the contextmanagement, resources-management, and opportunity-management arenas (Fig. 1) that are considered "incubators" of competitive advantage [Khota and Pretorius (2008a,b, 2009)]. From a product life cycle perspective these management focus areas should be encapsulated within an organization's Balanced Scorecard to ensure strategic priority.

Management need to learn to make the difficult choices quickly, compromise and deliberately differentiate, employ tactics such as "first to market," "operational excellence," and "customer relationship management" with a focus on competitiveness through effective implementation of those strategies (through customer centric, process driven, bottom-up, transformational, and leadership-driven management interventions) [Anderson (2005); Miyake (2002)]. Ultimately, customers are purchasing the utility of a product or service; the most successful companies are those that make it possible for customers to accomplish the functional need more easily, economically, or conveniently [Christensen et al. (2004); Norman (2005)]. In this sense the Balanced Scorecard concept is particularly useful.

The next section focuses specifically on the importance and impact of good knowledge management and IP as contributors and outcomes of good innovation management. 


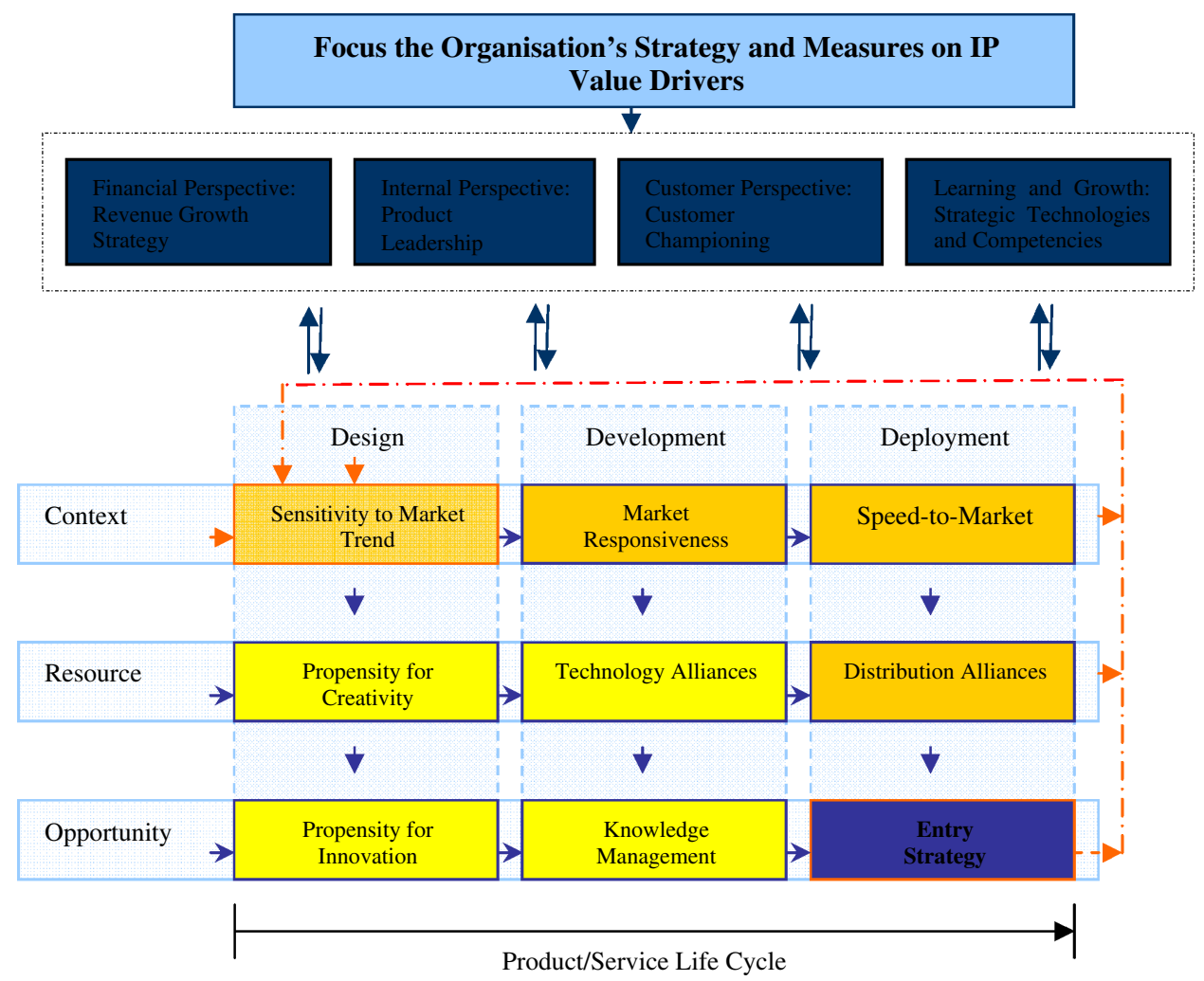

Fig. 1. The 3D Balanced Scorecard paradigm --- nine areas of strategic influence [Khota and Pretorius (2008a,b); Khota et al. (2004)].

\subsection{Context evolution and strategic stance}

Three aspects of product design - - - appearance, performance, and the ideas/memories the item evokes, influence the consumer's emotional reactions [Norman (2005)]. The emerging context and the approaching context over the horizon are to a large degree knowledge-driven [Wylie (2000)] (Table 1), with disruptive innovations (i.e., adequate, smaller, simpler, and cheaper innovations) defining new value propositions of companies in a value network where capabilities are underpinned by resources (people, technology, products, cash, channels, and brands), processes (recruitment, training, R\&D, manufacturing, market research, and budgeting) and values (ethics, customer demands, cost structures, risk tolerance, and emphasis on new opportunities) [Christensen and Raynor (2003); Christensen et al. (2004); Teece (2001)]. Paradoxically, great companies do not fail because they do bad things, but rather they fail because they keep doing better at the things that made them great [Christensen (1997)]. The successful companies are those that are able to recreate themselves to meet new competitive demands [Welborn and Kasten (2005)], where success is driven by: (i) the adaptation of resources, processes and values with the contextual trends introducing disruptive innovations [Christensen et al. (2004); Teece (2001)], (ii) where the best designs are driven by dynamic, flexible processes 
Table 1. Context trends (adapted from [Christensen and Raynor (2003); Wylie (2000)]).

\begin{tabular}{|c|c|}
\hline Historic trend & Emerging trend \\
\hline Valuing tangibles & Valuing intangibles \\
\hline Optimization strategies & Innovation strategies \\
\hline Focus on medium and delivery technology & Focus on content and presentation \\
\hline Valuing reproducible money and goods & $\begin{array}{l}\text { Valuing irreproducible time and infinitely } \\
\text { reproducible information }\end{array}$ \\
\hline Knowledge filtered by experts & Knowledge filtered by interested parties \\
\hline Resource restraints & Time restraints \\
\hline High entry costs & Low entry costs \\
\hline Equilibrium and stability & Sustainability and adaptation \\
\hline Current trend & Over the horizon \\
\hline Virtual "reality" & Post-virtual realities \\
\hline Focus on elements & Focus on context \\
\hline Knowledge generation and personal expertise & Knowledge utilization and group understanding \\
\hline Focus on text-centered literacy & Focus on multimedia and aural communication \\
\hline Solving problems & Seeking opportunities \\
\hline European and African lack of innovation & European and African innovation leadership \\
\hline Economies of scale & Economies of scope \\
\hline Additive measurement & Combinatory measurement \\
\hline Deregulation and freedom & Re-regulation according to agreed principles \\
\hline
\end{tabular}

[Norman (2005)], (iii) a competency to introduce products quickly, which creates competitive advantages and higher profitability [Cooper (2001)], and (iv) resource allocation that prioritizes projects based on cost/benefits analysis, maximization of R\&D, and new product exploration [Cooper (2001)].

Intangible assets (staff skills, strategic and process quality, patents, copyright and software, trademarks/brands, supplier and customer relationships etc.) are currently the key factors of production driving competitiveness [Hofmann (2005)].

Since much of the market valuation of companies today, particularly technology companies, is based on intangible assets (brands, IP, people) compared to the historical focus on tangible assets (property, plant and equipment), a management focus on leveraging and capitalizing on these assets is justifiable [Fairchild (2002); Hofmann (2005); Howrey (2001)]. In addition, globalization introduces increased vulnerability and necessity to protect proprietary information from being copied or stolen [Garelli (2006)].

In five separate field surveys conducted by the authors presented in earlier papers [Khota and Pretorius (2009); Khota (2008a)] to assess what the product development and business evaluation criteria are that successfully attract the interest of investors, it was found that (i) IP is indeed an increasingly important consideration by investors and lenders; and (ii) product development companies that are sensitized to these specific IP considerations are considered to be better placed to compete, generate profits, and attract funding from external investors. More specifically, it was found that:

- Most investors consider patents, trademarks, and copyrights to be important IP;

- A product's IP profile is an important consideration for outside investors; 
- A product's IP strategy influences the investment decisions;

- A greater emphasis will be placed on IP considerations by investors into the future; and

- Many companies currently have inadequate IP strategies in place.

An earlier survey conducted by Howrey [2001] among corporate analysts, yields that an effective IP strategy should encompass:

- Patent protection (which justifies R\&D spend);

- The use of IP to protect market position and prevent competitors from entering the market;

- An approach which balances the emphasis on IP and

tangibles; • Exploitation of potential; and

- Generating royalties through the patent portfolio.

The following are cited as economic reasons for an organizational management strategy that focuses on knowledge [Knapp (1998)]:

- The global perception of knowledge as a key asset;

- The rise of occupations that create and use knowledge; and

- The convergence of information and communication technologies.

Apart from technology, other organizational knowledge "enablers" include content, learning, culture, and leadership [Knapp (1998)].

From a strategic planning perspective, having a clear and effective IP strategy is thus deemed fundamental to a company's success and survival in the marketplace, and those who lack an effective IP strategy are generally not expected to become market leaders [Howrey (2001)]. Having a strategic tool, such as the IP Scorecard presented here, is considered an essential management aid in focusing attention on development and commercialization of technology innovations from an IP-centric perspective.

The next section explores what it means to be knowledge and IP-centric.

\subsection{Organizational empowerment through knowledge management}

Knowledge in organizations is seen in complex and broad terms, including structured data, patents, programs and procedures, intangible knowledge and capabilities of people, and novel and unique ways of doing business [Fairchild (2002)], where knowledge management encompasses the processes of innovation, knowledgecreation, knowledge acquisition, organization, application, sharing, and replenishment, all geared toward creating value from intellectual capital [Knapp (1998)].

The knowledge-centric organization thus seeks to create value by leveraging the following capital resources within the organization, which jointly provide a basis for knowledge creation and utilization [Fairchild (2002)]:

- Human capital: all individual capital (knowledge, skills, and experience);

- Intellectual capital (includes intangibles within knowledge, information and skills that can produce an asset of equal or greater importance than land, labor, and capital); • Structural capital (includes processes, structures, and systems); and 
- Social capital (Goodwill between people which promotes sharing, arising from physical and virtual interchanges).

Effective knowledge management, which justifies further management expenditure and attention, encompasses measurable benefits of knowledge implementation and the ability to exploit existing technology [Knapp (1998)]. As an example, IBM is a good case of effective knowledge management: The US Patent and Trademark O ffice's annual league table of corporate patent filing reveals that in 2000, IBM filed 2,886 patent applications - - - the income from licensing IP is one of IBM's fastestgrowing sources of profit (\$1.7bn: FY 2000) [IBM (2004)].

Fairchild [2002] cites four management perspectives emanating from knowledge: the value of knowledge from a balance sheet perspective, the market and technological exploitation of IP, the capturing of project-based learning, and the management of knowledge workers [Knapp (1998)].

While protecting and exploiting IP is the key to success, investors recognize that companies with significant IP assets have a competitive advantage, are likely to be more profitable and are more likely to survive a downturn [Howrey (2001)].

There is thus definite potential with respect to IP development and value creation, through appropriate IP strategy and management.

As further validation, the research conducted by the authors among venture capital investors [Khota (2008b)] indicates that there is a poor inclination toward technology/product development and commercialization investment opportunities with poor IP profile as reflected in Table 2 .

Section 3 discuss the IP Scorecard, a strategic management tool emanating through inductive reasoning from the exploratory research. This tool focuses management attention on strategic IP development and management with a view to value creation through IP.

\section{The IP/Knowledge Scorecard: A Conceptual Framework}

As a strategic management tool, the Balanced Scorecard method is used by many companies for defining the organization's strategy, creating targets and initiatives for implementing the strategy, measuring the results of such implementation, and

Table 2. Survey conducted among seven venture capital investors: summarized results.

There is a little or no novelty in the product/technology offering (i.e., lack of IP). Investors generally prefer supporting a product that displays clear novelty which enables competitive advantage based on its innovative attributes;

The opportunity fails to boast significant technology competitive advantages (i.e., lack of IP). In general, the greater the product's technology advantage the lower the perceived market risk by investors;

The opportunity fails to exhibit adequate IP protection claims whether formally or via trade secrets for the technology/products being developed (i.e., a poor product protection matrix structure surrounding the product). Investors also consider it essential in high technology investments that the inventor or technology developer plays an active and committed role in the new business venture. The findings of the IP survey (e.g., that investors consider the product's IP and the robustness of the IP strategy) and the literature study findings also suggest that the ranking of IP as an important criterion should escalate with time. 
creating feedback mechanisms for improving the strategy [IBM (2004); Kaplan and Norton (1996)]. From an innovation management perspective, while there are numerous management metrics within the financial and customers' areas of the Balanced Scorecard [Fairchild (2002); Kaplan and Norton (1996)], the current research seeks to explore metrics specifically within the internal and learning and growth areas, which create shareholder value.

Industry experts accept that learning and growing organizations are better positioned for strategic success into the future - - - The learning and growing organization is one, in which knowledge management activities are deployed and expanding in order to leverage the creativity of all the people in the organization [Kaplan and Norton (1996); Muralidhar (2005)].

In general, investors agree that better corporate information and strategic guidance on the company's intangible assets and their development or commercialization should directly impact on corporate valuations and the financing opportunities available as a result thereof [Hofmann (2005); Howrey (2001); Khota (2008a); Khota and Pretorius (2009); Lev (2004)].

Despite the limitations of accounting regulations, sensitivities toward protecting "company secrets" and the challenges surrounding exploiting intangible asset value (e.g., comparability, increased risk, valuation methods, and market skepticism), there is a real benefit for companies who do strategic planning around intangible assets [Hofmann (2005)]. Managing and creating "balance sheet" value from intangible assets should lead to more growth through: capital allocation optimization, investor confidence as a result of better information on intangible assets, and the appropriate market valuation of the company [Hofmann (2005)]. Enhancing the recognition of intangible assets as a viable form of collateral, through improved IP management and structuring, licensing etc., will improve the value attributed to such assets [Hofmann (2005); Teece (2001)].

Ultimately the monetary valuation of intangible assets will be guided by the following considerations of: (i) financial objective (loan, investment, or disposal), granularity (appraisal of individual intangibles (e.g., specific patents), knowledge intensive projects, whole business divisions or entire companies), and valuation perspective (internal or external valuator) [Hofmann (2005)]. While the cost-price, market-value, or income approaches may be used to value an intangible asset, the income approach is preferred most, since this method takes cognizance of the forecast earnings attributable to intangible assets specifically and uses the discounted cash flow (DCF) analysis on these future intangible driven earnings to indicate present value [Hofmann (2005)]. Lev [2004] provides more guidance on the actual valuation methodology of intangible assets.

In terms of strategic focus areas for value-optimization of IP, two key activities are necessary [Hofmann (2005)]:

- Intangible assets that are of particular relevance to the company-specific valueadded processes must be identified and analyzed; and

- The transmission methods by which central intangible assets are transformed into future revenues must be well understood. 
Ultimately however, an effective IP strategy is necessary. Conversely, an ineffective IP strategy consequentially results in an opportunity cost and R\&D inefficiencies that investors and external stakeholders frown upon, or competitors take advantage of to the detriment of the organization -- - Howrey [2001] cites British Telecom (BT) as such an example, losing massive opportunity by owning 15,000 patents protecting more than 1,700 inventions and yet failing to capitalize on these effectively.

\subsection{The Balanced Scorecard}

The Balanced Scorecard is a strategic management tool that promotes management attention metrics, data collection, and analysis from four key perspectives (i.e., learning and growth perspective, business process perspective, customer perspective, and financial perspective), aimed at motivating the organization and creating alignment between strategy and outcomes [Arveson (1998); Kaplan and Norton (2001)]. In general, organizations that make their strategy the central organizational agenda with incredible strategic focus and a mobilization of staff to act in fundamentally different ways, guided by the strategy, display exceptional performance [Kaplan and Norton (2001); Miyake (2002); Welborn and Kasten (2005)]. Key management activities of the Balanced Scorecard users who displayed exceptional performance have focused on implementing the strategic map (leadership, enterprise-wide operational strategic focus, organizational strategic alignment, personnel strategic commitment, and strategic evolution) [Kaplan and Norton (2001); Miyake (2002)], and aligning the organizational map with the scorecard of customers and alliance partners [Miyake (2002)].

The Balanced Scorecard can be the foundation for the strategic management of information and knowledge in organizations [Martinsons et al. (1999)], under the management category of learning and growth [Fairchild (2002)]. Product developers may refine the Balanced Scorecard even further by applying a "Product/Innovation Scorecard" [Khota and Pretorius (2008b)] that defines the strategy and performance measures for products and product innovations, and which provides strategic focus and execution for successful product evaluation, adoption, positioning, life-cycle management, and growth management [Sahu (2004b)]. The strategy-focused product innovation process encompasses: (i) mobilizing product innovation through leadership; (ii) translating the product innovation strategy into product development; (iii) aligning product design and development processes to the product innovation strategy; (iv) making product innovation strategy every product engineers job; and (v) making product innovation strategy a continuous process [Kaplan and Norton (2001); Sahu (2004b)] (Fig. 2).

The conceptual IP Scorecard presented is the result of the literature review and inductive reasoning employed within the nine focal areas identified in the 3D Balanced Scorecard [Khota and Pretorius (2008a,b); Khota et al. (2004)] mentioned earlier and the IP product protection matrix [Khota and Stern (2005)].

\section{The Key Strategic Management Focus Areas Driven by IP and Knowledge Management}




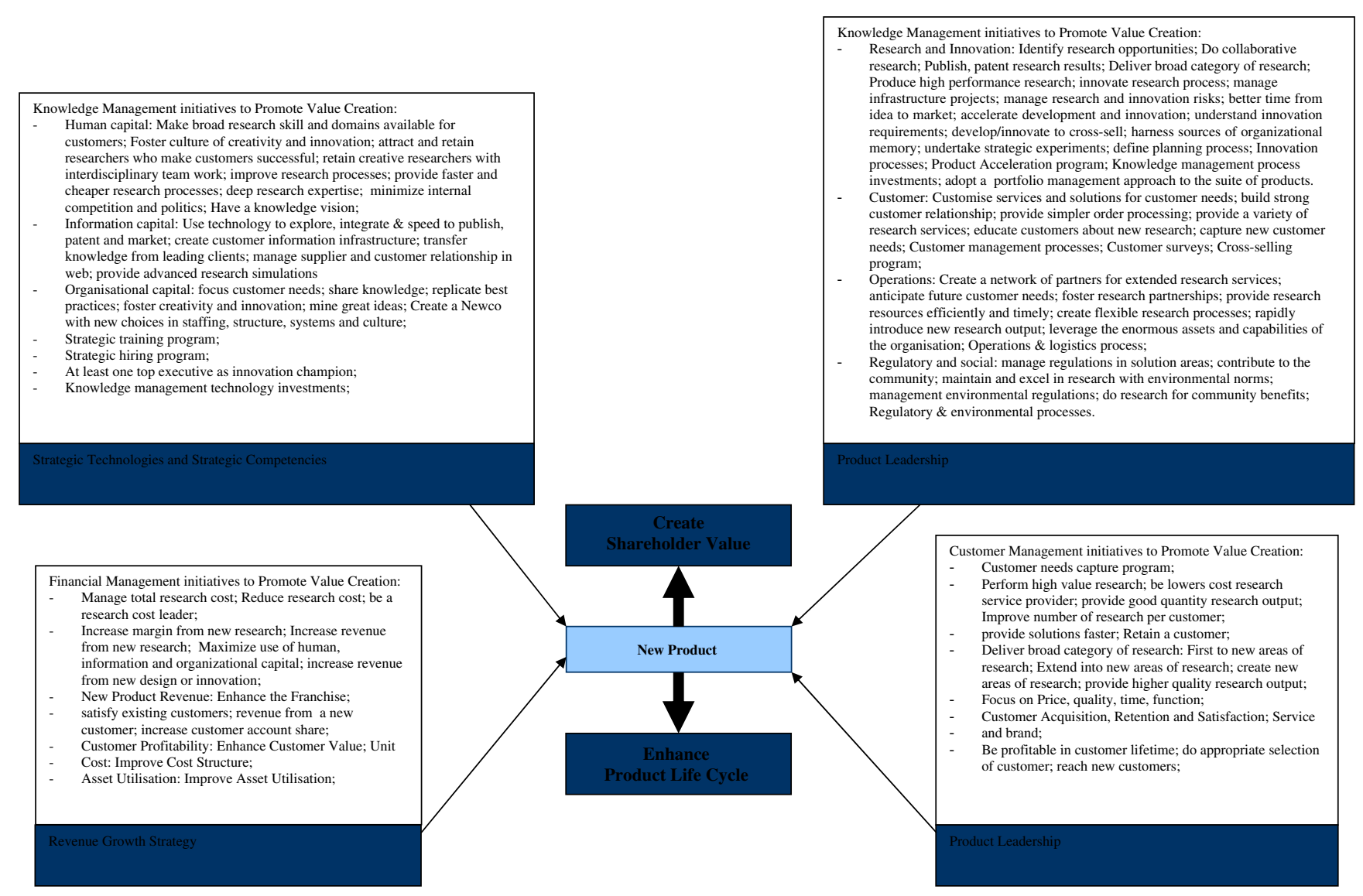

Fig. 2. BSC/R\&D Strategy map --- focusing strategy on IP and product innovation (adapted from [Coburn (2006); Fairchild (2002); Govindarajan and Trimble (2005); Kaplan and Norton (2004); Johannson (1996); Mouritsen et al. (2001); Sahu (2004a,b); Stalk and Lachenauer (2004); Teece (2001); Von Krogh et al. (2000)]. 
Within the knowledge economy, knowledge "ownership" and capitalization are measures of success for management. This economy thus warrants the prioritization of the "Internal Drivers" (indicated in Fig. 3) that improve and promote knowledge and IP ownership and utilization, and customer-centric knowledge-sharing aspects (i.e., the knowledge-based aspects of the "Customer Drivers" indicated in Fig. 3),

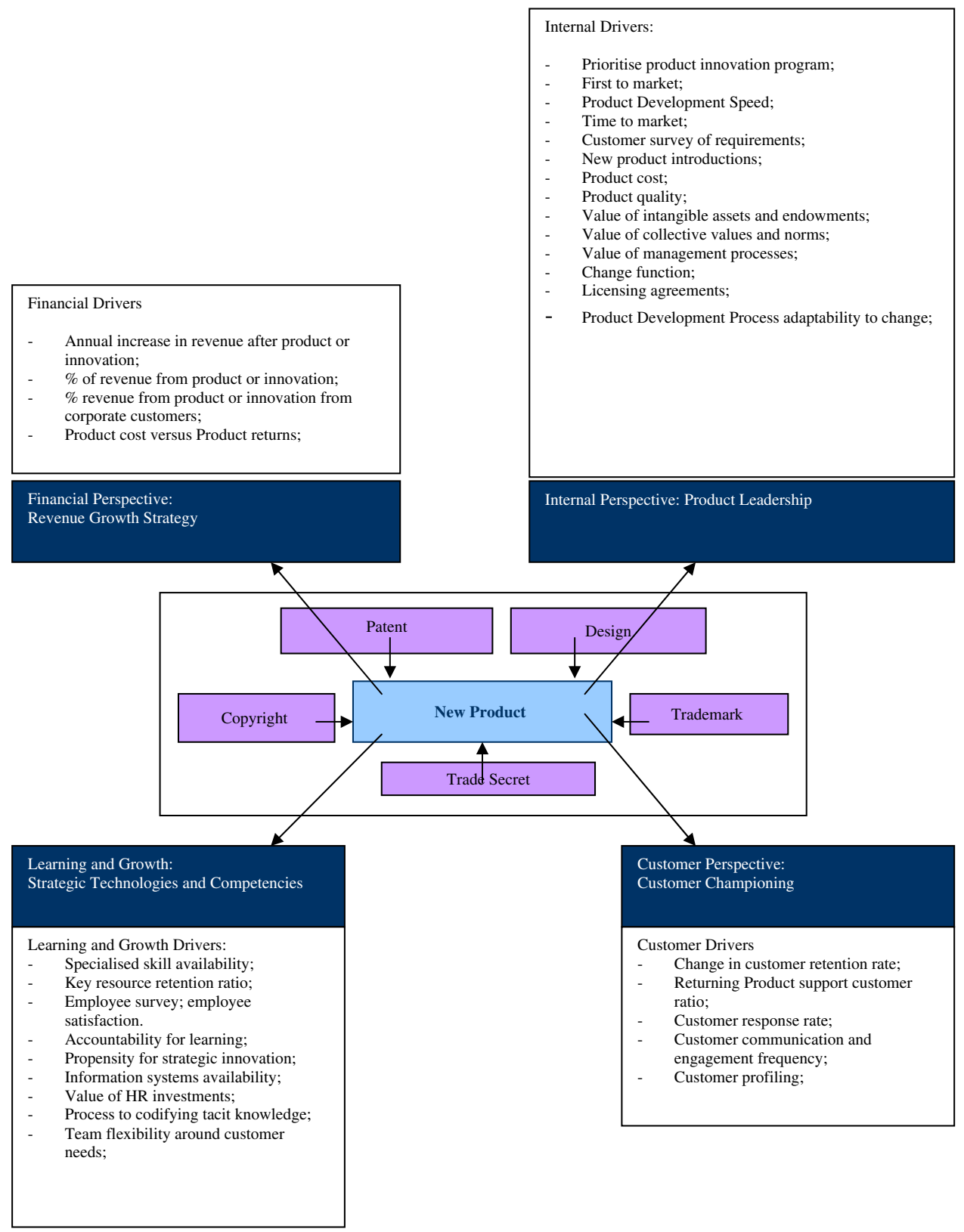

Fig. 3. The knowledge-centred BSC/product development metrics (adapted from [Fairchild (2002); Khota and Stern (2005); Mouritsen et al. (2001); Sahu (2004b)]. 
and the direct impact of these metrics on the other perspectives. Using these prioritized metrics in conjunction with an "IP Product Protection Matrix" approach [Khota and Stern (2005)] that seeks to economically exploit all the IP characteristics of a product to enhance its value (including patent, copyright, design, and trade mark), this value-driven portfolio management approach to IP and product development should ensure strategic leadership within the knowledge economy.

In general, the rate of failure for high-tech products is high, due to a poor rate of acceptance of new technology by consumers [Coburn (2006)]. As a management innovation measure, instead of focusing only on new features and low costs, companies developing high-tech products should focus on what their customers think and feel about their products and tailor product innovation to address the needs of this market i.e., the "change function," which says that the customers' desire for the product must outweigh their reluctance to adapt to something new," must drive innovation, rather than "Moore's Law" or "Grove's Law" [Coburn (2006)].

Revolutionizing a business requires strategic innovations (which encompasses unproven business models) through strategic experiments, which are hard to predict and budget for [Govindarajan and Trimble (2005)], with investments in research and development that necessarily seek to promote continual learning, growth, and development of internal processes in order to satisfy customer needs and to achieve the financial goals of shareholders [Sahu (2004a)]. Strategy maps for the R\&D organization includes the management activities within the Balanced Scorecard as indicated in Fig. 2.

Businesses must use knowledge management to survive and advance [Von Krogh et al. (2000)]. The value of intangible assets is achieved with how these assets are aligned with the strategy of the R\&D initiatives [Sahu (2004a)], which encompass consideration of strategic job families (i.e., jobs with greatest impact on the strategy), strategic IT portfolio (i.e., high-impact technology investments) and organizational change agenda (i.e., organizational cultural change mechanisms), targeting either complete research solutions, low total cost R\&D and/or research leadership (Fig. 3 provides a holistic view of R\&D BSC considerations).

In general, the implications emanating from the field research and literature study suggests several key areas where management activity should be focused. These include inter alia that (i) the management should create incentives for new product development that creates value through IP generation; (ii) it should encourage thirdparty collaboration that seeks to generate IP rights and that are protected; (iii) it should be sensitized to the intrinsic value of its organization's dormant IP and its commercial potential; (iv) it should create a "freedom to operate" paradigm: freedom to sell, develop, grow in any country and in any place; (v) it should strategically target creating and exploiting IP in its primary markets; and (vi) it should manage the pace of change through continual training, new skills acquisition, capex/R\&D, and targeting/retaining people of value.

With respect to strategic management of IP, management should seek to (i) develop new IP and protect existing IP; (ii) pursue patenting/and formal registration opportunities arising from innovative designs; (iii) develop an "effective" IP development strategy; (iv) have a very strict attitude on IP infringement; and 


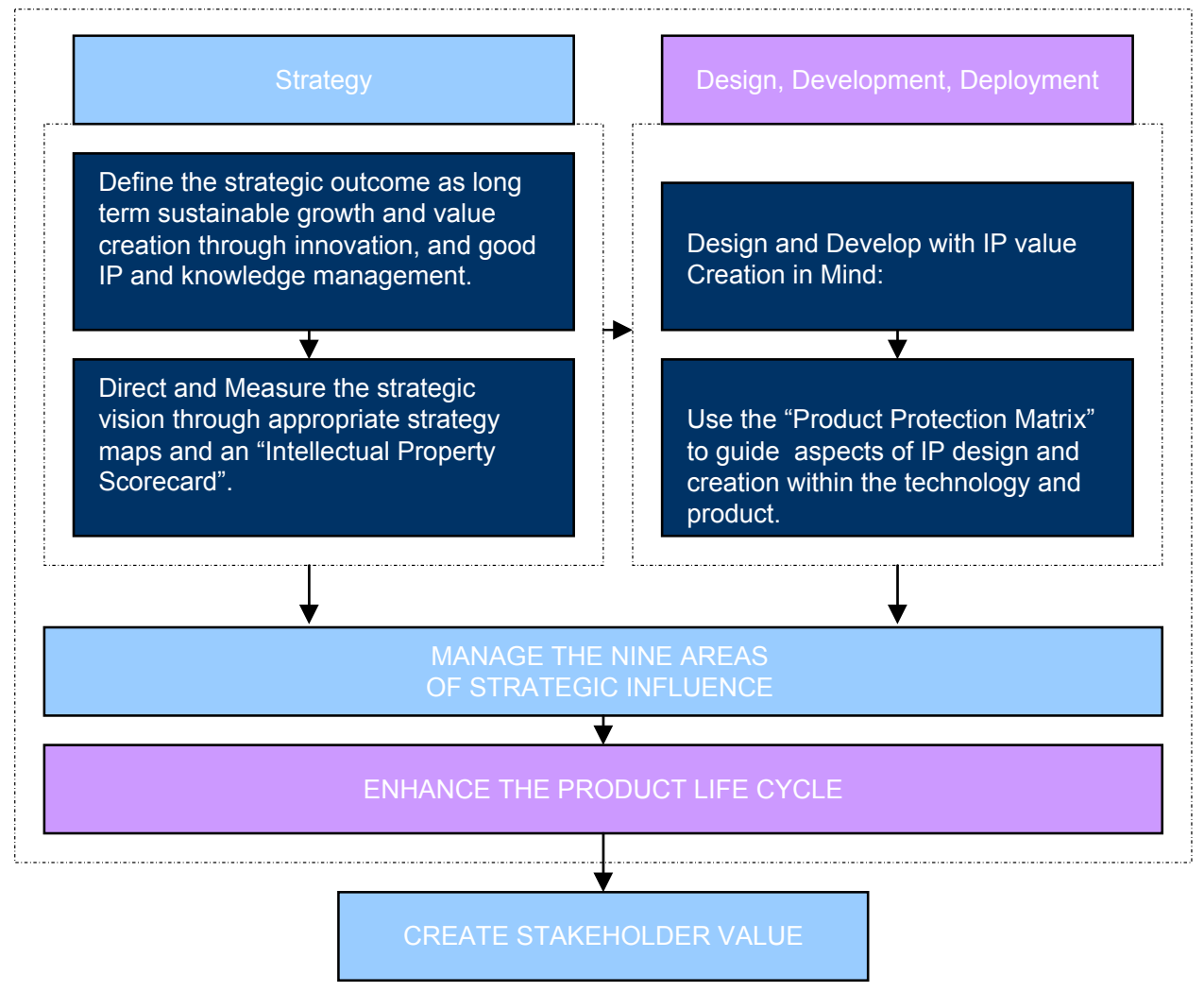

Fig. 4. Strategic framework for harvesting IP-based value potential.

(v) avail all resources (skills, capital, instruments, monitoring) to develop and protect IP in broad terms.

\section{Conclusion}

The knowledge economy demands a strategic management focus on knowledgebased outcomes. The research supports a holistic IP-centric value creation approach to strategic product development that effectively manages all stakeholders' interests. A focus on innovation as a growth and development strategy is imperative for longterm leadership and value creation.

The frameworks and scorecards reflected in this paper have been successfully and conceptually developed through exploratory research, inductive reasoning, and limited field research reported on and published previously.

Through a management focus on the nine management areas broadly defined as the 3D-Balanced Scorecard paradigm within the product development life cycle, the context, resource, and, opportunity arenas are expected to be optimized toward the strategic intent of leadership. Delivering on that management focus requires the harvesting of knowledge and IP as the key ingredient in the knowledge economy. This necessarily mandates in the first instance a product protection matrix approach 
to product development. This also necessitates a management convergence and obsession of resources on identifying, codifying, collaborating, and capitalizing on IP and knowledge creation. This should ultimately be recognized through a significant increase in the number of "intangible asset" line entries that appear on the balance sheet, representing the value created through good IP management. Converging on such strategic management through tools such as the IP Scorecard (indicated in Fig. 2 above) must seek ultimately to deliver on the key management question: "Are we creating and leveraging IP to create and enhance stakeholder value?"

The management strategic priority is that whatever the IP-activity being undertaken (including licensing out of knowledge assets, technology transfer agreements, cross-licensing etc.), ultimately companies must seek to recover and enhance value from knowledge, IP and innovation, across the product life cycle in order to carve out financial success. This requires a coherent strategic management focus on IP, encompassing inter alia utilizing IP-centric strategic management tools (including the IP Scorecard) to focus management activities on value creation across and within the context, resources, and opportunity arenas. See Fig. 4.

\section{References}

Anderson, D. (2005). If You Don't Make Waves You'll Drown - 10 Hard-Changing Strategies for Leading in Politically Correct Times. Hoboken, NJ, John Wiley \& Sons.

Arveson, P. (1998). What is the Balanced Scorecard. http://www.balancedscorecard.org/ basics/bsc1.html, accessed 09 November 2006 .

Baker, P. (2008). From Concept to Consumer - How to Turn Ideas Into Money. New York, NY, FT Press.

Barloworld (2007). Supply Chain Foresight Survey-200\%. Barloworld Logistics. http://www. barloworld-logistics.com.

Business Day (2004). South Africa Needs to File More Patents. 10 September. http://www. scidev.net/News/index.cfm?fuseaction $=$ readNews\&itemid $=1594 \&$ language $=1$, accessed 27 February 2007.

Christensen, C. M. (1997). The Innovator's Dilemma - When New Technologies Cause Great Firms to Fail. Boston, MA, Harvard Business School Press, Harvard Business School Publishing Corporation.

Christensen, C. M. and Raynor, M. E. (2003). The Innovator's Solution - Creating and Sustaining Successful Growth. Boston, MA, Harvard Business School Press, Harvard Business School Publishing Corporation.

Christensen, C. M., Anthony, S. D. and Roth, E. A. (2004). Seeing What's Next - Using the Theories of Innovation to Predict Industry Change. Boston, MA, Harvard Business School Press, Harvard Business School Publishing Corporation.

Coburn, P. (2006). The Change Function - Why Some Technologies Take Off and Others Crash and Burn. New York, NY, Portfolio Division. Penguin Group (USA) Inc.

Cooper, D. R. and Schindler, P. S. (2006). Business Research Methods, Ninth edition. New York, NY, McGraw-Hill.

Cooper, R. G. (2001). Winning at New Products - Accelerating the Process from Idea to Launch, 3 rd edition. Cambridge, MA, Perseus.

Fairchild, A. M. (2002). Knowledge management metrics via a balanced scorecard methodology. In Proceedings of the 35th Hawaii International Conference on System Sciences. http:// csdl2.computer.org/comp/proceedings/hicss/2002/1435/08/14350243.pdf, accessed 13 November 2006. 
Farber, S. (2004). The Radical Leap — A Personal Lesson in Extreme Leadership. Chicago, Dearborn.

Garelli, S. (2006). The World Competitiveness Landscape in 2006. IMD World Competitiveness Yearbook 2006. IMD World Competitiveness Centre. http://www.imd.ch/research/centers/wcc/index.cfm, accessed 09 November 2006.

Govindarajan, V. and Trimble, C. (2005). Ten Rules for Strategic Innovators - From Idea to Execution. Boston, MA, Harvard Business School Press.

Hancock, J. (2005). Investing in Corporate Social Responsibility - A Guide to Best Practice. Business Planning $\& 5$ the UK's Leading Companies. Sterling, VA, Kogan page.

Hofmann, J. (2005). Value Intangibles! - Intangible capital can and must be valued owners and valuers alike will benefit. Deutsche Bank Research, 19 October 2005. http:// www.dbresearch.com.

Howrey (2001). A Survey of Investor Attitudes on IP Protection. http://www.howrey.com/ docs/UK_IP_Survey0102.pdf, accessed 08 January 2007.

IBM (2004). Using a Balanced Scorecard to Tie the Result Act to Your Day-to-Day Operational Priorities. IBM Business Consulting Services, Institute for the Study of Public Policy Implementation. September. http://spa.american.edu/isppi/documents/leadership_pr es1_ 2004-09-28.pdf, accessed 21 November 2006.

IDC (2007). Venture Capital Strategic Business Unit — Industry Analysis. Industrial Development Corporation of South Africa Ltd.

Jackson, K. T. (2004). Building Reputational Capital Strategies for Integrity and Fair Play that Improve the Bottom Line. Oxford, NY, Oxford University Press.

Johannson (1996). Human Resource Costing and Accounting. http://www.sveiby.com.au/ IntangAss/OECDartUlfjoh.htm. Cited in [Fairchild (2002)].

Kaplan, R. and Norton, D. (1996). Translating Strategy into Action. Boston, MA, Harvard Business School.

Kaplan, R. and Norton, D. (2001). The Strategy-Focused Organisation. Boston, MA, Harvard Business School Press.

Kaplan, R. S. and Norton, D. P. (2004). Strategy Maps - Converting Intangible Assets into Tangible Outcomes. Boston, MA, Harvard Business School Press.

Khota, I. (2008a). IP SURVEY: A Survey of South African Investor Attitudes on IP Protection. University of Johannesburg, South Africa.

Khota, I. (2008b). Survey/interviews conducted amongst Venture Capital Investors. Venture Capital Strategic Business Unit. Industrial Development Corporation of South Africa.

Khota, I. (2009). A Model for Creating incubators of Strategic Advantage in Product Development - A Context, Resources and Opportunity Perspective. Unpublished Doctoral Thesis. University of Johannesburg.

Khota, I. and Pretorius, L. (2008a). Embedded innovation — Strategic management incubators for knowledge hegemony. South African Journal of Industrial Engineering, 19, 1: 105-118. http://findarticles.com/p/articles/mi_qa5491/is_200805/ai_n25501283.

Khota, I. and Pretorius, L. (2008b). Intellectual property scorecard: strategically capitalising on value created by innovation and R\&D. In Proceedings PICMET Portland International Conference, 27-31, July: 584-592. http://www.picmet.org/new/conferences/2008/bulletin08.pdf, accessed 25/06/2009.

Khota, I. and Pretorius, L. (2009). Sustainable change-driven-innovation: a Private Equity/ Investor and IP hierarchy perspective for new product development companies. In South African Institute of Industrial Engineering Conference, October.

Khota, I. and Stern, A. (2005). Leveraging intellectual property for strategic product development advantage. South African Journal of Information Management, 7, 4.

Khota, I. et al. (2004). Strategic positioning for new-context product and service leadership. In South African Institute of Industrial Engineering Conference, September. Indaba Hotel. http://www.saiie2009.co.za, accessed 11 January 2010.

Knapp, E. (1998). Knowledge management. Business \& Economic Review, 44, 4: 3-6. 
Krakoff, C. (2003). Key Potential Export Markets and The Market Access Barriers Facing Southern African Exporters. The Services Group, South African Global Competitiveness Hub. http://www.satradehub.org, accessed 08 November 2006.

Lev, B. (2001). Intangibles: Management, Measurement and Reporting. Washington, Brookings Institution.

Lev, B. (2004). Sharpening the intangibles edge. Harvard Business Review, 82, 6: 108-116.

Luecke, R. and Katz, R. R. (2003). Managing Creativity and Innovation. Boston, MA, Harvard Business School Press.

Macdonald, I. (2006). Benchmarking Progress — SA Improves Global Competitiveness. 11th May 2006. http://www.sagoodnews.co.za, accessed 09 November 2006.

- Martinsons, M. et al. (1999). The balanced scorecard: A foundation for the strategic management of information systems. Decision Support Systems, 25: 71-88.

Marton-Lefevre, J. et al. (2003). Invention and Innovation For Sustainable Development. Report of Lemelson-MIT Program and LEAD International, School of Engineering, Massachusetts Institute of Technology. http://web.mit.edu/Invent/n-pressreleases/ downloads/sustainable.pdf, accessed 09/06/2009.

Miyake, D. (2002). Implementing Strategy with the Balanced Scorecard: An Introduction to the Strategy-Focused Organization. http://www.dmreview.com, accessed 11 November 2006.

Mouritsen, J. et al. (2001). Reading an intellectual capital statement: describing and prescribing knowledge management strategies. In Proceedings of the 4 th Intangibles Conference, Stern School of Business, New York University, May 2001.

Muralidhar, S. (2005). The Balanced Scorecard and Knowledge Management. http://www. deccanherald.com/deccanherald/Jul132005, accessed 13 November 2006.

Ncube, S. (2007). Respondent to Legal Team Questionnaire: Developing a Strategic Management Model for Promoting Product Competitive Advantages. Principal IP Legal Advisor, Sasol Limited.

Norman, D. (2005). Emotional Design - Why We Love (or Hate) Everyday Things. New York, NY, Basic Books.

Pouris, A. (2005). Technological performance judged by America patents awarded to South African inventors. South African Journal of Science, 101: 221-224.

Romm, C. (2007). Respondent to Legal Team Questionnaire: Developing a Strategic Management Model for Promoting Product Competitive Advantages. IP Law Manager, Anglo Platinum Corporation.

Sahu, P. (2004a). Describing research and development using strategy maps. In IEEE-UT Engineering Management Conference. University of Texas, Austin, TX.

Sahu, P. (2004b). Strategy-focused product innovation with product scorecard and product innovation scorecard. In IEEE-UT Engineering Management Conference. University of Texas, Austin, TX.

Stalk, G. and Lachenauer, R. (2004). Hardball - Are You Playing to Play or Playing to Win? Boston Consulting Group. Boston, MA, Harvard Business School Press.

Steinhobel, B. (2007). Respondent to Product Team Questionnaire: Developing a Strategic Management Model for Promoting Product Competitive Advantages. Product Team Leader, Steinhobel Designs.

Teece, D. J. (2001). Managing Intellectual Capital - Organizational, Strategic and Policy Dimensions. Oxford, Oxford University Press.

Ulrich, D. and Smallwood, N. (2003). Why the Bottom Line Isn't! - How to Build Value Through People and Organizations. Hoboken, NY, John Wiley \& Sons.

UN (2008). Innovation for Sustainable Development - Local Case Studies From Africa. United Nations, New York. http://www.un.org/esa/sustdev/publications/africa_case studies/index.htm, accessed 16 June 2009.

Von Krogh, G. et al. (2000). Enabling Knowledge Creation - How to Unlock the Mystery of Tacit Knowledge and Release the Power of Innovation. Oxford, NY, Oxford University Press. 
WEFORUM (2006a). Going for Growth. World Economic Forum on Africa 2006. 31 May 2006. http://www.weforum.org/en/knowledge/Events/2006/WorldEconomicForumon Africa, accessed 08 November 2006.

WEFORUM (2006b). Technologies for African Growth. World Economic Forum on Africa 2006. 1 June. http://www.weforum.org/en/knowledge/Events/2006/WorldEconomic ForumonAfrica, accessed 08 November 2006.

WEFORUM (2007). Global Competitiveness Report 2006-2007. World Economic Forum. http://www.weforum.org, accessed 08 November 2006.

Welborn, R. and Kasten, V. (2005). Get It Done! - A Blueprint for Business Execution. Hoboken, NJ, John Wiley \& Sons.

Wylie, J. (2000). The Economics of Intangible Value — Trends. Trend Monitor International. http://www.entovation.com/assessment/trends.htm, accessed 01 July 2008.

XYZ (2007). Legal Team Questionnaire: Developing a Strategic Management Model for Promoting Product Competitive Advantages. Interview/Survey conducted amongst selected reputable IP Legal Practitioners to assess challenges and best practice with respect to IP development and exploitation within the South African Context. May.

\section{Biography}

Irfaan Khota has been serving as an investment banking professional for the past 10 years, as Corporate Financier, Transaction Advisor, Project Financier and Venture Capitalist, within Standard Corporate Merchant Bank, RizQapital Corporate, and the Industrial Development Corporation in South Africa. He joined the Venture Capital Business Unit of the IDC in 2007, where he is currently an investment principal managing and assessing investment opportunities into new High Technology startups. He has served as Telecommunications Engineer, Project Manager, Business Manager and Divisional Head within Transtel Ltd between 1996 and 2003.

Irfaan completed his Bachelor in Electrical Engineering degree at the Rand Afrikaans University (RAU) in 1996. In 1998 Irfaan was awarded a master's degree in engineering management and in 1999 a BCom (Hons) degree in Investment Management, at RAU. In 2001 he was awarded an MBA for fulltime study at the Wits Business School where he received a distinction for his MBA dissertation. In 2009 Irfaan was awarded a PhD from the Faculty of Engineering at the University of Johannesburg for his research work there under the guidance of Professor Leon Pretorius. He has conducted reading at HEC (France), is an alumni from the Executive Programme in Venture Capital at the Haas School of Business UCLA, and has undertaken readings in Innovative Futures with Stanford University.

Irfaan has contributed to several peer review journals, conferences, and has served as external examiner to several master research dissertations at the University of Johannesburg.

Leon Pretorius has more than 35 years professional, engineering, academic, and academic management experience. He was professor at the University of Johannesburg, South Africa until 2007. In 2004 he was the last Dean of Engineering at the Rand Afrikaans University (UJ) prior to the merger of RAU and Technikon Witwatersrand (TWR) when he became Executive Dean of Engineering and the 
Built Environment at the University of Johannesburg in 2005. He is currently Professor in the Graduate School of Technology Management at University of Pretoria. He has concurrently been active as specialist consultant and researcher in engineering industry since 1980. He has supervised more than 160 master and $\mathrm{PhD}$ students in engineering as well as engineering and technology management. He has also published more than 150 technical conference papers and peer reviewed journal articles as author and co-author in his fields of expertise. 
